\title{
Pengaruh Permainan Logico Terhadap Kemampuan Berhitung di Taman Kanak-Kanak Aisyiyah Bustanul Athfal Kayu Gadang
}

\author{
Annisa Busril \\ Universitas Negeri Padang \\ annisabusril31@gmail.com \\ Farida Mayar, Delfi Eliza \\ Universitas Negeri Padang \\ Email: faridamayar@gmail.com, deliza.zarni@gmail.com
}

\begin{abstract}
Numeracy is part of the mathematical activities needed to develop children's knowledge of numbers, numbers, addition and subtraction. The aim of this study was to determine the effect of the Logico game on children's numeracy skills in Aisyiyah Bustanul Athfal Kayu Gadang Kindergarten. The population in this study is Aisyiyah Bustanul Athfal Kayu Gadang Kindergarten. Samples in group B1 and B2 group research. Based on the analysis results obtained tcount> ttable is 2.0794> 2.05553 and proved with a significant level $a$ $0.05 \mathrm{dk}=26$, means the hypothesis $\mathrm{H} 1$ is accepted and Ho is rejected, there is a significant difference between the results of the numeracy ability of the experimental group children who use games Logico and control classes use kindergarten children. It can be concluded that the Logico game has an effect in increasing children's numeracy skills in Aisyiyah Bustanul Athfal Kindergarten Kayu Gadang.
\end{abstract}

Keywords : Logico; Counting Ability; Child Worksheet

\section{Abstrak (Bahasa Indonesia; 11 pt Tahoma)}

Berhitung adalah bagian dari kegiatan matematika yang dibutuhkan dalam mengembangkan pengetahuan anak tentang angka, bilangan, penjumlahan dan pengurangan. Tujuan penelitian ini adalah untuk mengetahui pengaruh permainan Logico terhadap kemampuan berhitung anak di Taman Kanak-kanak Aisyiyah Bustanul Athfal Kayu Gadang. Populasi pada penelitian ini yaitu Taman Kanak-Kanak Aisyiyah Bustanul Athfal Kayu Gadang. Sampel dalam penelitian kelompok B1 dan Kelompok B2. Berdasarkan hasil analisis diperoleh thitung $>$ ttabel yaitu 2,0794 $>2,05553$ dan dibuktikan dengan taraf signifikan a $0,05 \mathrm{dk}=26$, berarti hipotesis $\mathrm{H}_{1}$ diterima dan $\mathrm{H}_{\circ}$ ditolak, terdapat perbedaan yang signifikan antara hasil kemampuan berhitung anak kelompok eksperimen yang menggunakan permainan Logico dan kelas control menggunakan Anak Taman Kanak-Kanak. Dapat disimpulkan bahwa permainan Logico berpengaruh dalam peningkatan kemampuan berhitung anak di Taman Kanak-kanak Aisyiyah Bustanul Athfal Kayu Gadang.

Kata Kunci : Logico; Kemampuan Berhitung; Lembar Kerja Anak 


\section{PENDAHULUAN}

Kegiatan yang penting dalam kehidupan manusia adalah pendidikan. Melalui pendidikan manusia dapat belajar untuk mencapai kemandirian prestasi dan berinteraksi dengan perubahan kehidupan. Kemampuan yang perlu ada pada anak dalam mengenal angka dan bilangan yaitu berhitung. Pendidikan pada anak usia dini adalah pendidikan yang sangat penting, mereka sangat menyenangi melakukan pengamatan, eksplorasi, berimajinasi, menemukan, melakukan penyelidikan, mengumpulkan informasi dan berbagi pengalaman. (Eliza, 2013). Pengembangan keterampilan dasar di TK mencakup beberapa aspek. Salah satunya adalah keterampilan pengembangan atau bahasa. Pengembangan keterampilan bahasa di TK dilaksanakan dengan mengembangkan keterampilan mendengarkan, berbicara, membaca dan menulis (Eliza, 2014).. Berdasarkan hasil penelitian (Elvi Yulianti, 2019), Pengenalan Literasi Numerasi diperoleh hasil bahwa role playing berpengaruh dalam pengenalan literasi numerasi pada anak di Taman Kanak-kanak Twin Course Pasaman Barat. Sejalan dengan penelitian ini (Amelia Anggun Besmah, 2019), melakukan penelitian tentang Pengaruh Kegiatan Role Playing With Music Terhadap Pengembangan Karakter Social Care Anak di TK dan diperoleh hasil kegiatan role playing with music lebih menarik bagi anak daripada menggunakan kegiatan bermain peran mikro. Berdasarkan observasi awal peneliti pada bulan Februari 2019 di kelas B1 bersama Ibu Syafrida selaku guru kelas B1 Taman Kanak-kanak Aisyiyah Bustanul Athfal Kayu Gadang menunjukkan bahwa kurangnya penggunaan metode permainan dalam kegiatan berhitung, anak belum mampu menyebutkan lambang bilangan secara urut 1-10 dengan benar. Terlihat dalam kegiatan pembelajaran, anak diminta untuk menyebutkan lambang bilangan sampai "sepuluh" anak akan terhenti pada lambang bilangan "enam" atau "tujuh" dan ketika anak akan melanjutkan penyebutan lambang bilangan selanjutnya anak langsung menyebutkan bilangan "delapan" sehingga bilangan enam dan tujuh terlewati. Anak belum bisa mencocokkan lambang bilangan dengan dengan benar. Hal tersebut terlihat dari kegiatan anak dalam bermain kartu bergambar. Ketika anak menghitung gambar yang ada di kartu dan mencocokkan dengan angka yang seharusnya angka 7 tetapi anak mencocokkan angka 5 . 
Selain itu permainan yang menarik bagi anak haruslah permainan yang nyaman digunakan oleh anak atau tidak membahayakan serta cara memainkannya permainan tersebut juga sederhana dan penyajiannya tidak lama karena membuat anak merasa jenuh dan bosan. Salah satu permainan yang dapat menunjang anak dalam mengembangkan kemampuan berhitung adalah permainan logico. Kemampuan berhitung anak perlu diajarkan kepada anak sejak dini, karena kemampuan berhitung dapat menunjang keberhasilan belajar anak selanjutnya. Pembelajaran berhitung harus menggunakan media dan permainan. Hikmah (2016) mengemukakan bahwa hasil penelitian menunjukkan bahwa melalui permainan kartu angka dapat mengembangkan kemampuan berhitung. Dilanjutkan oleh Subekti (2014) hasil penelitian menunjukkan bahwa melalui permainan tradisional dapat mengembangkan kemampuan berhitung anak. Berdasarkan hasil penelitian di atas dapat disimpulkan bahwa kemampuan berhitung dapat dikembangkan melalui permainan yang menarik bagi anak. Umama (2016) menyatakan permainan logico menggunakan media 2D, permainan logico tidak mengharuskan anak menggunakan alat tulis manapun cukup gameboard. Penggunaan alat permainan logicopada anak usia dini bertujuan untuk dapat belajar mandiri sambil bermain, mampu berhitung dan memecahkan masalah.

Beberapa hal yang harus dilakukan oleh guru TK dalam mengoptimalkan kemampuan berhitung anak diantaranya adalah menyajikan permainan yang menyenangkan bagi anak dengan memiliki warna yang mencolok agar perhatian anak tertarik pada permainan tersebut, menvariasikan permainan dan membuat atau memakai alat peraga yang menarik agar anak tidak jenuh dengan media yang sama setiap harinya. Salah satu media pembelajaran yang dapat meningkatkan kemampuan kognitif yaitu dengan menggunakan permainan Logico. Permainan Logico dapat meningkatkan pemahaman anak terhadap konsep bilangan. Umama (2016) menyatakan permainan Logico menggunakan media 2D, permainan logico tidak mengharuskan anak menggunakan alat tulis manapun cukup gameboard. Penggunaan alat permainan logico pada anak usia dini bertujuan untuk dapat belajar mandiri sambil bermain, mampu berhitung dan memecahkan masalah. Penelitian mengenai permainan Logico sebelumnya telah dilakukan oleh (Munifah, 2018) diperoleh hasil bahwa Permainan Logico membuat anak-anak asyik bermain dan betah sekaligus mengembangkan imajinasi, mengembangkan keterampilan berpikir logis matematis, 
mengembangkan keterampilan motorik serta sebagai wahana untuk berkomunikasi. Tujuan dari penelitian ini adalah untuk mengetahui pengaruh permainan Logico terhadap kemampuan berhitung anak di Taman Kanak-kanak Aisyiyah Bustanul Athfal Kayu Gadang.

\section{METODOLOGI}

Metodologi penelitian menggunakan pendekatan kuantitatif dengan jenis penelitian quasy experimental (eksperimen semu). Metode penelitian kuantitatif yaitu metode penelitian yang berlandaskan pada filsafat positivism, digunakan untuk meneliti pada populasi atau sampel tertentu (Sugiyono, 2012). Teknik pengambilan sampel dilakukan secara random, pengumpulan data menggunakan instrumen penelitian, analisis data bersifat kuantitatif/statistik dengan tujuan untuk menguji hipotesis yang telah ditetapkan. Penelitian ini bertujuan untuk mengetahui pengaruh permainan Logico terhadap kemampuan berhitung anak di Taman Kanak-kanak Aisyiyah Bustanul Athfal Kayu Gadang dengan membandingkan hasil belajar antara kelas kelompok eksperiment dengan hasil belajar dari kelas kelompok kontrol. Dari rancangan penelitian kelas eksperiment diberikan perlakuan/treatment $(\mathrm{X})$ kepada kemampuan dari mengenal angka demgan permainan Logico. Pada kelas kelompok kontrol tidak diberi perlakuan yang serupa yaitu menggunakan Anak Taman Kanak-Kanak, kelas-kelas tersebut diberi pre-test, treatment dan post test.

Tabel 1. Rancangan Penelitian

\begin{tabular}{|l|l|l|l|}
\hline \multicolumn{1}{|c|}{ Kelompok } & Pretest & Perlakuan & Posttest \\
\hline Eksperimen & $\mathrm{O} 1$ & $\mathrm{X}$ & $\mathrm{O} 2$ \\
\hline Kontrol & $\mathrm{O} 3$ & - & $\mathrm{O} 4$ \\
\hline
\end{tabular}

Keterangan:

$01=$ Pre-test kelas eksperimen

$\mathrm{O} 3=$ Pre-test kelas kontrol

$\mathrm{X}=$ Perlakuan dalam hal ini pemberian permainan Logico

$\mathrm{O} 2=$ Post-test kelas eksperimen

$04=$ Post-test kelas kontrol

Populasi pada penelitian ini yaitu Taman Kanak-Kanak Aisyiyah Bustanul Athfal Kayu Gadang dengan jumlah 46 anak dan terdiri dari kelas B1, B2, dan B3. Menurut (Sugiyono, 2017) Purposive Sampling merupakan teknik penetuan sampel dengan pertimbangan tertentu. Pertimbangan ini berdasarkan keputusan dari kepala sekolah kepada peneliti dalam mengambil sampel peneliti yaitu 
kelompok B1 dan B2. Sampel penelitian adalah kelompok B1 (eksperiment) dan Kelompok B2 (kontrol).

\section{HASIL DAN PEMBAHASAN}

File Pada penelitian ini terdapat 2 kelompok yakni file hasil Pre-test kelas kelompok eksperiment (KB1) dan kelas control (KB2) kepada pengenalan angka ketika sebelum diberi treatment.

Tabel 2. Rekapitulasi Hasil Pre-test Perkembangan Berhitung Anak di Kelas Eksperimen (B2) dan Kelas Kontrol (B1)

\begin{tabular}{lcc}
\hline \multirow{2}{*}{ variabel } & \multicolumn{2}{c}{ Pembelajaran } \\
\cline { 2 - 3 } & $\begin{array}{c}\text { Eksperimen } \\
\text { B2 }\end{array}$ & Kontrol B2 \\
\hline N & 14 & 14 \\
Nilai Tinggi & 68,75 & 68,75 \\
Nilai Rendah & 50 & 50 \\
Jumlah Nilai & 812,5 & 800 \\
Median & 62,75 & 54,5 \\
Rata-Rata & 58,03 & 57,14 \\
SD & 6,43 & 5,71 \\
SD & 41,34 & 32,60 \\
\hline
\end{tabular}

Berdasarkan tabel 2 di atas, kelompok eksperiment dengan jumlah anak 14 orang memperoleh nilai tertinggi 68,75 dan nilai terendah 50 . Dari nilai anak kelompok eksperiment ini diperoleh nilai secara keseluruhan yaitu 812,5 dengan rata-rata sebesar 58,03 standar deviasinya 6,34 dan nilai variansnya 41,34.

Sedangkan kelompok kontrol dengan jumlah anak 14 orang memperoleh nilai tertinggih 68,75 dan nilai terendah 50. Dari nilai kelompok kontrol ini diperoleh jumlah secara keseluruhannya yaitu 800 dengan rata-rata nilainya sebesar 57,14 standar deviasinya 5,71 dan nilai variansinya 32,60 .

Berdasarkan deskripsi pada tabel 2, dapat diketahui bahwa kemampuan dikelompok eksperiment lebih tinggi dibandingkan dengan kelompok kontrol dalam kemampuan berhitung pada anak. Untuk lebih jelasnya dapat dilihat pada grafik 3 dibawah ini. 


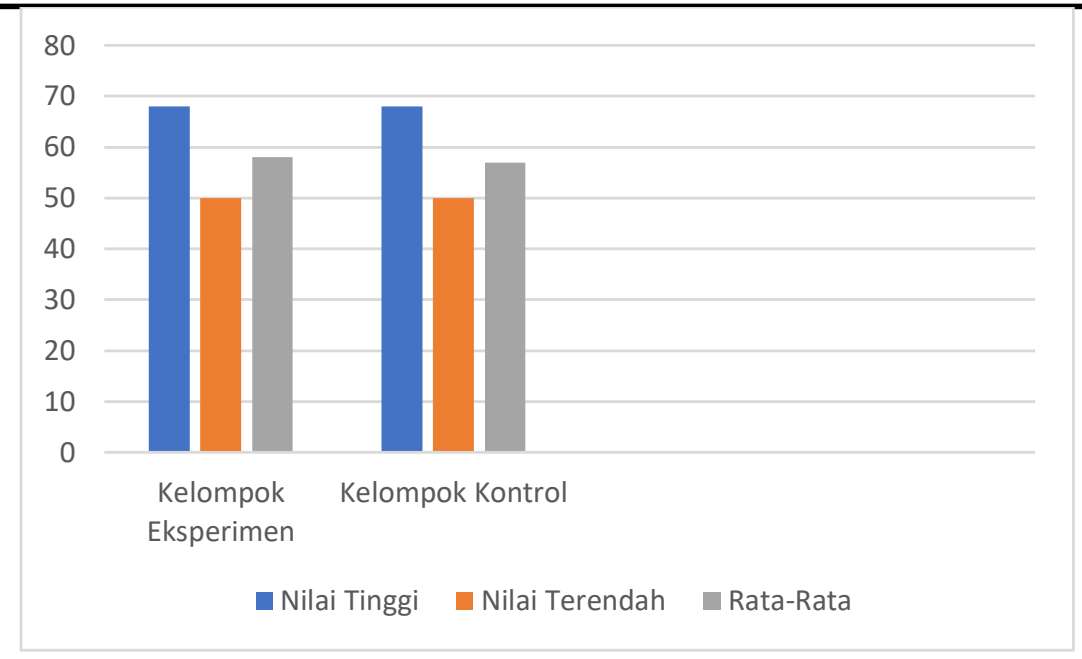

Gambar 1. Data Perbandingan Hasil Pre-test Perkembangan Berhitung Anak Kelas Eksperimen dan Kelas Kontrol

Tabel 3. Rekapitulasi Hasil Post-test Perkembangan Berhitung Anak di Kelas Eksperiment dengan Logico dan Kelas Kontrol Menggunakan Anak Taman Kanak-Kanak

\begin{tabular}{lcc}
\hline \multirow{2}{*}{ variabel } & \multicolumn{2}{c}{ Pembelajaran } \\
\cline { 2 - 3 } & $\begin{array}{c}\text { Eksperimen } \\
\text { B2 }\end{array}$ & Kontrol B2 \\
\hline N & 14 & 14 \\
Nilai Tinggi & 100 & 87,5 \\
Nilai Rendah & 68,75 & 62,5 \\
Jumlah Nilai & $1.181,25$ & 1.075 \\
Median & 81,91 & 73 \\
Rata-Rata & 84,37 & 76,78 \\
SD & 9,95 & 8,65 \\
SD & 99 & 74,82 \\
\hline
\end{tabular}

Berdasarkan tabel diatas dapat diketaui bahwa kemampuan dikelompok kelas eksperimen lebih tinggi dibandingkan dengan kelompok kelas kontrol dalam kemampuan berhitung pada anak. Untuk lebih jelasnya dapat dilihat pada grafik 2 di bawah ini: 


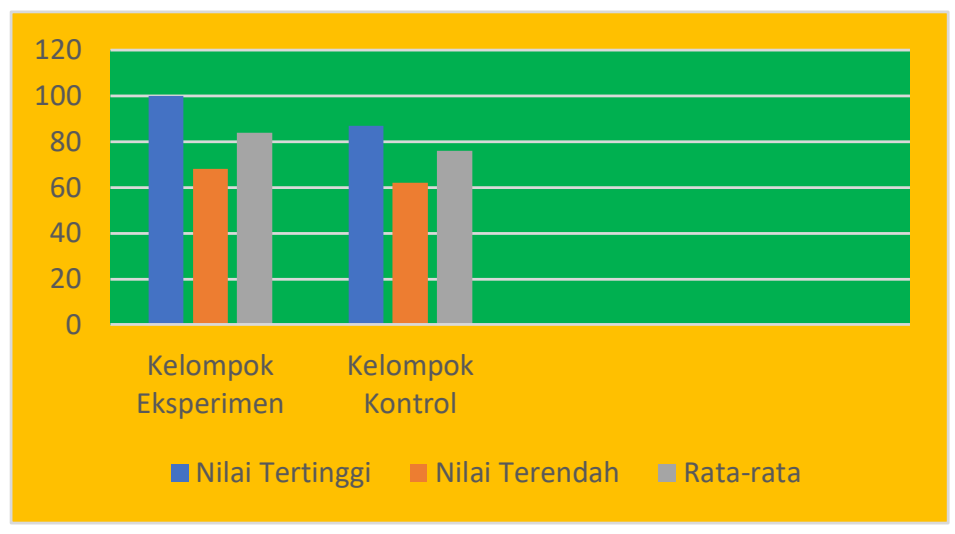

Gambar 2. Data Perbandingan Hasil Post-test Perkembangan Berhitung Anak Kelas Eksperimen dan Kelas Kontrol.

Berdasarkan hasil pre-test perkembangan berhitung anak pada kelompok eksperimen dan kelompok kontrol diperoleh angka rata-rata kelompok eksperimen yaitu 58,03 sedangkan angka rata-rata kelompok kontrol yaitu 57,14. Dari hasil analisis data yang telah dilakukan bahwa sebesar 0,37394 dibandingkan dengan $\mathrm{a}=0,05$ (tabel 2,05553) dengan derajat kebebasan $d k\left(N_{1}-1\right)+\left(N_{2}-1\right)=26$. Dengan demikian thitung $<t_{\text {tabel }}$, yaitu 0,37394<2,05553 maka dapat dikatakan bahwa hipotesis $\mathrm{H}_{1}$ ditolak $\mathrm{H}_{0}$ diterima. Sehingga dapat disimpulkan bahwa tidak terdapat perbedaan yang signifikan antara hasil pre test kemampuan berhitung anak dikelompok eksperimen dengan kelompok kontrol sebelum diberikan treatment. Ini berarti kemampuan berhitung anak pada tes kemampuan awal (Pre-Test) sama atau tidak memiliki perbedaan yang signifikan.

Kemudian diberikan treatment atau perlakuan pada kelompok, berdasarkan hasil Post-test kemampuan berhitung anak yang diberikan pada kelompok eksperimen diperoleh nilai rata-rata 84,37 dan nilai rata-rata kelas kontrol yaitu 76,78. Berdasarkan hasil analisis data yang telah dilakukan bahwa thitung sebesar 2,0794 dibandingkan dengan $a=0,05$ (ttabel $=2,05553$ ) dengan derajat kebebesan $d k\left(\mathrm{~N}_{1}-1\right)+\left(\mathrm{N}_{2}-1\right)=26$. Dengan demikian thitung $>$ tabel yaitu $\mathbf{2 , 0 7 9 4}$ $>2,05553$ maka dapat dikatakan bahwa hipotesis $\mathrm{H}_{0}$ ditolak dan $\mathrm{H}_{1}$ diterima. Dapat disimpulkan bahwa terdapat pengaruh yang signifikan kemampuan berhitung pada anak di Taman Kanak-kanak Aisyiyah Bustanul Athfal Kayu Gadang.

Penelitian ini menggunakan Logico di kelas (B1) Taman Kanak-kanak Aisyiyah Bustanul Athfal Kayu Gadang, semua anak terlihat antusias dan bersemangat untuk mencobanya karena pembelajaran berhitung menggunakan permainan Logico ini terbilang baru bagi anak terutama pada Taman Kanak-kanak Aisyiyah Bustanul 
Athfal Kayu Gadang dapat dilihat dari ekspesi awal anak ketika peneliti memperlihatkan permainan Logico kepada anak. Anak secara berebut untuk melihat dan memegang permainan Logico tersebut dan anak-anak juga tidak mau tenang dalam bertanya tentang permainan Logico, melalui permainan Logico ini mampu membuat konsep matematika yang abstrak menjadi lebih konkrit.

Sedangkan di kelas kontrol menggunakan majalah atau LKA yang disedikan oleh sekolah. Pada kelas kontrol terlihat bahwa tidak semua anak memperhatikan guru dalam mengejarkan majalah atau LKA sehingga anak tidak mengerti dalam mengerjakan, ada anak yang bermenung, anak melihat kiri kanan, bermain, mengobrol dengan teman, bernyanyi dan ada yang berjalan-jalan di dalam kelas. Hal ini terjadi karena anak telah bosan menggunakan majalah atau LKA untuk kegiatan belajar berhitung.

Selanjutnya, guru menyuruh anak mewarnai dan menghitung gambar yang ada di majalah, masih ada anak yang menghitung tidak sesuai dengan urutan gambar yang diwarnai sehingga hasil yang dihitung anak kadang tidak sesuai dengan jumlah gambar yang diwarnai terdapat di dalam majalah. Serta dalam menghubungan jumlah gambar dengan angka anak masih kesulitan dan keliru sehingga ketika jumlah gambar 4 (empat) anak menghubungkan dengan angka 3 (tiga).

Jadi, hasil kemampuan berhitung pada anak di kelas eksperimen lebih baik dari pada hasil kemampuan berhitung pada anak di kelas kontrol, dapat dilihat dari rata-rata anak kelas eksperimen yang lebih tinggi dari pada kelas kontrol. Karena keunggulan dari permainan Logico adalah permaina yang menarik bagi anak, anak bisa mencocokkan jumlah gambar dengan jumlah bilangan dengan cara menggeser tombol sesuai dengan bulatan yang ada di gambar yang di hitung anak.

Kemudian anak selesai menghitung gambar dan mencocokkan warna gambar dengan tombol bulatan warna. Setelah itu anak bisa hasil akhir dengan cara guru membalikan gambar dan mencocokkan jawaban anak dengan kuci jawaban yang telah dibuat oleh guru. Permainan ini membuat anak lebih semangat melakukan kegiatan berhitung, serta anak dapat melakukan kegiatan berhitung dengan benda konkrit karena untuk alat permainan seperti ini anak tidak dapat menemukannya dan di sekolah pun jarang guru melakukan kegiatan berhitung dengan alat permainan. Anak selalu menunggu alat permainan ini untuk digunakannya. Maka dapat disimpulkan bahwa permainan Logico lebih mempengaruhi kemampuan berhitung pada anak, serta memberi pengetahuan tentang lambang bilangan dan 
konsep bilangan serta anak dapat berfikir logis melalui pengamatan terhadap benda-benda konkrit.

\section{SIMPULAN}

Permainan Logico berpengaruh dalam peningkatan kemampuan berhitung anak di Taman Kanak-kanak Aisyiyah Bustanul Athfal Kayu Gadang

\section{DAFTAR PUSTAKA}

Amelia Anggun Besmah, dkk. 2019. Pengaruh Kegiatan Role Playing with Music Terhadap Pengembangan Karakter Social Care Anak di TK. Jurnal Warna Vol.3, No.2.

Bahfen, Munifah. 2018. Meningkakan Keterampilan Berfikir Logis Matematis Melalui Permainan Logico. Jurnal Pendidikan Anak Usia Dini. Vol 2, No.2.

Elvi Yulianti, Indra Jaya, Delfi Eliza. 2019. Pengaruh Role Playing terhadap Pengenalan Literasi Numerasi di Taman Kanak-Kanak Twin Course Pasaman Barat. Aulad : Journal on Early Childhood 2019, 2(2), Pages 41-50 ISSN : 2655-4798 (Printed); 2655-433X (Online).

Eliza, Delfi. 2013. Penerapan Model Pembelajaran Kontekstual Learning (CTL) Berbasis Centra di Taman Kanak-Kanak. Jurmal IImiah IImu Pendidikan. Vol.XIII, No. 2.

Eliza, Delfi. 2014. Reading Readiness of Kindergarten Students of At-Taqwa Mosque East Jakarta. Indonesian Journal of Early Childhood Education Studies. 3(1) (2014) 1-6.

Hikmah, Qoyumil dkk. 2016. Peningkatan Kemampuan Berhitung Pada Anak Kelompok B Melalui Permainan Kartu Angka di TK Dharma Indria I Kecamatan Patrang Kabupaten Jember Tahun Pelajaran 2015/2016. Jurnal Edukasi. III (2). 39-42.

Subekti, Ambar. 2014. Pengaruh Permainan Tradisional Terhadap Kemampuan Berhitung Pada Anak TK B PAUD Cahaya Cemerlang Aisyiyah Puntukrejo Karanganyar. Jurnal PAUD STKIP. Vol 2 No 1. 1-10.

Sugiyono. 2017. Metode Penelitian pendidikan pendekatan Kuantitatif, Kualitatif, dan $R \& D$. Bandung: Alfabeta.

Umama. 2016. Pojok Bermain Anak. Jogjakarta: CV Diandra Primamitra Media. 